NBER WORKING PAPER SERIES

\title{
INTELLECTUAL PROPERTY RIGHTS, FOREIGN DIRECT INVESTMENT, AND INDUSTRIAL DEVELOPMENT
}

\author{
Lee Branstetter \\ Kamal Saggi \\ Working Paper 15393 \\ http://www.nber.org/papers/w15393 \\ NATIONAL BUREAU OF ECONOMIC RESEARCH \\ 1050 Massachusetts Avenue \\ Cambridge, MA 02138 \\ October 2009
}

The authors thank seminar audiences at the University of Adelaide, University of Melbourne, University of New South Wales, University of Sydney, and the University of Wollongong for helpful comments. The theoretical model presented in this paper builds upon and extends that presented in Branstetter, Fisman, Foley, and Saggi (2007). We thank Ray Fisman and Fritz Foley for their contributions to that earlier work and for useful comments on this research. All errors remain our own. Views expressed are those of the authors and do not necessarily reflect those of the Bureau of Economic Analysis or the National Bureau of Economic Research.

(C) 2009 by Lee Branstetter and Kamal Saggi. All rights reserved. Short sections of text, not to exceed two paragraphs, may be quoted without explicit permission provided that full credit, including $\odot$ notice, is given to the source. 
Intellectual Property Rights, Foreign Direct Investment, and Industrial Development

Lee Branstetter and Kamal Saggi

NBER Working Paper No. 15393

October 2009

JEL No. F23,F43,O31,O34,O41

\begin{abstract}
$\underline{\text { ABSTRACT }}$
This paper develops a North-South product model in which Southern imitation and the North-South flow of foreign direct investment (FDI) are endogenously determined. In the model, a strengthening of IPR protection in the South reduces the rate of imitation, which, in turn, increases the flow of FDI. The increase in FDI more than offsets the decline in production undertaken by Southern imitators, so that the South's share of goods produced by the global economy increases. Furthermore, real wages of Southern workers increase even though prices of goods produced by multinationals exceed those of Southern imitators. The preceding results hold when Northern innovation is endogenously determined; in addition, the rate of innovation increases with a strengthening of Southern IPR protection.
\end{abstract}

Lee Branstetter

Heinz School of Policy and Management

and Department of Social and Decision Sciences

Carnegie Mellon University

2504B Hamburg Hall

Pittsburgh, PA 15213

and NBER

branstet@andrew.cmu.edu

Kamal Saggi

Southern Methodist University

Department of Economics

PO Box 750496

Dallas, TX 75275-0496

ksaggi@smu.edu 


\section{Introduction}

How does the strengthening of intellectual property rights (IPRs) protection by developing countries impact their industrial development? How does it affect their ability to attract foreign direct investment (FDI)? These and related questions have been at the heart of an ongoing debate that was brought into sharp relief during the negotiations preceding the ratification of the WTO's Agreement on Trade Related Aspects of Intellectual Property Rights (TRIPS) in 1995. Opposition to stronger IPR regimes in developing countries rests on two general arguments. First, there is concern that consumer welfare may be adversely impacted by enhancing the monopoly powers of innovators. Second, there is fear that stronger IPR protection in developing countries will hamper their ability to absorb foreign technologies without having any appreciable effect on Northern innovation. ${ }^{1}$ On the other side, TRIPS supporters argue that stronger IPRs world-wide will not only increase incentives for innovation but also foster industrial development in developing countries by encouraging multinationals to shift production there. In this paper, we seek to illuminate this important debate by developing a North-South product cycle model in which Southern imitation as well as the North-South flow of FDI respond endogenously to changes in the degree of Southern IPR protection available to Northern firms. Building on the research tradition established by Grossman and Helpman (1991), the model provides a unified framework for assessing some of the key arguments for and against stronger IPR regimes in developing countries.

The theoretical product cycle literature on the effects of Southern IPR protection has been built on two types of growth models analyzed in great detail in Grossman and Helpman (1991) - the variety expansion model and the quality ladders model. Important contributions to this literature were subsequently made by Helpman (1993) and Lai (1998) both of which uti-

\footnotetext{
${ }^{1}$ For example, a critic of stronger IPR enforcement in developing countries may argue that the rapid postwar industrialization in East Asian countries such as Japan and South Korea was achieved under relatively weak IPR regimes and that a premature imposition of a strong IPR regime could retard the industrial development of today's developing countries. See Maskus (2000), who notes these arguments, and the overview and evidence presented in Ordover (1991) and Maskus and McDaniel (1999). On South Korea, see Westphal, Kim, and Dahlman (1985). For criticisms of stronger IPRs which stress static welfare losses, see McCalman (2001) and Chaudhuri et al. (2006).
} 
lized the variety expansion model and Glass and Saggi (2002) who adopted the quality ladders approach. This research established that the effects of increased IPR protection in the South on the Northern rate of innovation depend very much on whether production shifts to the South via imitation of Northern firms or via North-South FDI. Furthermore, Helpman (1993) forcefully drove home the point that while stronger Southern IPR protection can indeed increase the pace of Northern innovation, such a policy change does not necessarily benefit the South since it reallocates production in favor of Northern firms whose prices tend to be higher than those of Southern ones. Thus, international production shifting matters not just for the nature and the extent of innovation but also welfare. Accordingly, we develop a North-South product cycle model with two important features. First, Like Lai (1998), the level of North-South FDI responds endogenously to changes in the degree of Southern IPR protection. Second, like Grossman and Helpman (1991b), imitation is treated as a costly activity and the Southern rate of imitation is endogenously determined. ${ }^{2}$

To ease the exposition of our main results and to focus on the effects of Southern IPR protection on activities that occur in the South - i.e. Southern imitation, production by local firms, and production by Northern multinationals - we first analyze a benchmark model in which imitation and FDI are endogenous whereas innovation is exogenously given. The results obtained in this benchmark model are then shown to hold when the rate of Northern innovation is endogenously determined. Apart from tractability, an important advantage of the simpler model is that it allows us to analyze the effects of a strengthening of Southern IPR protection when it does not have any effect on the Northern rate of innovation. This is important because opposition to stronger IPRs in the South is often based on the premise that since Northern innovation is unlikely to respond to changes in the South's IPR regime, the South does not have much to gain from such a policy change. As our analysis below shows, this position is not entirely correct.

Making both imitation and FDI endogenous helps push forward the literature on North-South product cycle models of international trade. Furthermore, since imitation is a costly activity in the real world, analyses that treat it as exogenous fail to capture how changes in the Southern IPR regime

\footnotetext{
${ }^{2}$ Helpman (1993) noted that "...imitation is an economic activity much the same as innovation; it requires resources and it responds to economic incentives...".
} 
alter the allocation of Southern resources among imitation and production. In addition to realism, an important reason for treating imitation as an endogenous activity is that North-South product cycle models with exogenous imitation have yielded remarkably different conclusions regarding the relationship between imitation and innovation from those that have treated it as endogenous. In a model with endogenous imitation and innovation, Grossman and Helpman (1991b) uncovered a positive relationship between the two activities while Lai (1998) found that a decline in the (exogenously given) rate of imitation leads to an increase in innovation if Northern firms can undertake FDI in the South. ${ }^{3}$ Our model sheds light on the relationship between innovation and imitation when both FDI and imitation are endogenously determined.

In our model, a strengthening of IPR protection in the South reduces the incentive of Southern firms to imitate Northern multinationals. This decline in imitation makes the South a more attractive location for Northern multinationals. Furthermore, we find that the intra-regional reallocation of Southern production (from local imitators to Northern multinationals) that results from a strengthening of Southern IPR protection is dominated by the accompanying inter-regional reallocation of production: in other words, the share of the global basket of goods produced in the South increases with a strengthening of Southern IPR protection.

Our analysis also provides some interesting insights with respect to the effects of Southern IPR protection on prices and wages in the two regions. First, by making the South a more attractive location for production and thereby shifting labor demand from the North to the South, a strengthening of IPR protection by the South lowers the North's relative wage. ${ }^{4}$ Second, since Northern multinationals charge lower prices relative to firms that produce in the North, the increase in FDI helps lower prices. However, this beneficial effect on prices is partially offset by the intra-regional reallocation of Southern production from local imitators to multinationals since a typical

\footnotetext{
${ }^{3}$ It is worth noting here that results also depend upon the type of innovation being considered: the quality ladders model of Glass and Saggi (2002) and Glass and Wu (2007) behave rather differently from the variety expansion models analyzed in our paper.

${ }^{4}$ This result contrasts with those of Krugman (1979) and Grossman and Helpman (1991b) who found a negative relationship between Southern imitation and the North's relative wage. Our result differs because imitation targets multinationals in our model whereas it targets Northern producers in theirs.
} 
imitator charges a lower price than a multinational. Due to the nature of pricing behavior under Dixit-Stiglitz (1977) preferences (prices are mark-ups over marginal costs), these changes in prices and nominal wages translate into clear-cut effects on real wages in the two regions: while Northern real wages decline due to stronger Southern IPR protection, Southern real wages increase. More specifically, the purchasing power of Southern workers in terms of Northern goods increases whereas their ability to purchase goods produced by Southern imitators and multinationals remains unaffected.

As noted earlier, a key argument in favor of weak IPR protection in the South is that Southern imitation lowers prices. Since Southern imitators price below Northern multinationals, this channel is also operative in our model. However, this argument ignores the labor market effects of international production shifting induced by stronger IPR protection in the South. By contrast, in our model, a strengthening of IPR protection by the South raises real wages of its workers. ${ }^{5}$

In Section 4 of the paper we show that all of the preceding results regarding wages, prices, and the allocation of production across regions as well as within the South continue to hold when the Northern rate of innovation is endogenously determined. The main additional result that emerges under endogenous innovation is that a tightening of IPR protection in the South raises the rate of innovation. As in Lai (1998), this happens due to two reasons. One, the reduction in imitation risk increases the duration for which Northern multinationals enjoy their profit stream and since all Northern firms are free to become multinationals, the reward to innovation goes up. Second, the reduction in imitation risk implies a greater North-South flow of FDI and this helps move Northern resources from production into innovation.

The relationship between FDI and IPR protection has received significant empirical scrutiny in the literature. ${ }^{6}$ As the survey by Park (2008) notes, as far as US data is concerned, there appears to be a clear positive relationship between the degree of IPR enforcement in developing countries and investment by US firms - see, for example, Lee and Mansfield (1996) and Nunnenkamp and Spatz (2004). Results derived from non-US data portray a

\footnotetext{
${ }^{5}$ The real wage effects captured by our model would not arise in partial equilibrium models that ignore the labor market effects of IPR reforms. Furthermore, such effects should only be expected to arise when IPR reforms are undertaken on an economy-wide basis as opposed to being focused on a few sectors.

${ }^{6}$ For a nuanced and detailed discussion of this literature, see Maskus (2000).
} 
more mixed picture: while Mayer and Pfister (2001) find a negative effect of stronger patent rights on location decisions of French multinationals, Javorcik (2004) finds that stronger patent rights in Eastern Europe and former Soviet Union states have a positive effect on FDI in high-technology sectors. The most recent and perhaps the most relevant empirical study for our purposes is that by Branstetter, Fisman, Foley, and Saggi (2007). They investigate the impact of IPR reform on multinational production by analyzing the responses of U.S. multinationals to a series of well-documented IPR reforms by sixteen countries in the 1980s and 1990s. Consistent with our model, they find that U.S.-based multinationals expand the scale of their activities in reforming countries after IPR reform. They also analyze U.N. industry-level data from reforming countries and show that industry-level value added increases after reforms, particularly in technology-intensive industries. ${ }^{7}$

Given the central role of FDI in our model, it is worth noting that, consistent with a large number of empirical studies discussed in Markusen (1995), we also find that an increase in the productivity of Northern R\&D leads to an increase in the flow of FDI as well as in the sales of Northern multinationals. Furthermore, we show that the use of FDI incentives by the South in the form of a reduction in the tax rate on the profits earned by multinationals has effects quite like those of IPR reform: it increases North-South FDI, real wages in the South, as well as the Northern rate of innovation. These results not only help clarify the structure of our model but are also quite relevant because incentives toward FDI are widespread in the global economy (UNCTAD, 2003) and a host of recent firm-level empirical studies document a negative relationship between FDI (particularly by US firms) and host country tax rates. ${ }^{8}$

The rest of the paper is organized as follows. Section 2 presents our benchmark model. Sections 3 describes the effects of a strengthening of Southern

\footnotetext{
${ }^{7}$ Following Feenstra and Rose (2000), they also construct for each reforming country an annual count of "initial export episodes" - the number of 10-digit commodities for which recorded U.S. imports from a given country exceed zero for the first time. This serves as a rough indicator of the net rate at which production shifts to the reforming countries, capturing changes in multinational production as well as indigenous imitation. This net rate of production shifting increases sharply after IPR reform, suggesting that any decline in indigenous imitation is more than offset by the increase in the range of goods produced by multinational affiliates.

${ }^{8}$ See, for example, Desai et. al. (2004) and Mutti and Grubert (2004).
} 
IPR protection on FDI, Southern production, wages, and prices. Section 4 presents the fully endogenous model and also considers the effects of Southern tax reductions toward Northern multinationals. Section 5 concludes while Section 6 constitutes the appendix.

\section{Model}

Consider a world comprised of two regions: North and South. Labor is the only factor of production and region $i$ 's labor endowment equals $L^{i}, i=N, S$. As in Grossman and Helpman (1991b), preferences are identical in the two regions and a representative consumer chooses instantaneous expenditure $E(\tau)$ to maximize utility at time $t$ :

$$
U=\int_{t}^{\infty} e^{-\rho(\tau-t)} \log D(\tau) d \tau
$$

subject to the intertemporal budget constraint

$$
\int_{t}^{\infty} e^{-r(\tau-t)} E(\tau) d \tau=\int_{t}^{\infty} e^{-r(\tau-t)} I(\tau) d \tau+A(t) \text { for all } t
$$

where $\rho$ denotes the rate of time preference; $r$ the nominal interest rate; $I(\tau)$ instantaneous income; and $A(t)$ the current value of assets. The instantaneous utility $D(\tau)$ is given by

$$
D=\left[\int_{0}^{n} x(j)^{\alpha} d j\right]^{\frac{1}{\alpha}}
$$

where $x(j)$ denotes the consumption of good $j ; n$ the number of goods available and $0<\alpha<1$.

As is well known, under the above assumptions, the consumer's optimization problem can be broken down into two stages. First, he chooses how to allocate a given spending level across all available goods. Second, he chooses the optimal time path of spending. The instantaneous utility function $D$ implies that the elasticity of substitution between any two goods is constant and equals $\varepsilon=\frac{1}{1-\alpha}$ and demand for good $j$ (given expenditure $E$ ) is given by

$$
x(j)=\frac{E p(j)^{-\varepsilon}}{P^{1-\varepsilon}}
$$


where $p(j)$ denotes the price of good $j$ and $P$ a price index such that

$$
P=\left[\int_{0}^{n} p(j)^{1-\varepsilon} d j\right]^{\frac{1}{1-\varepsilon}}
$$

Furthermore, as is well known, under the two-stage procedure the optimal spending rule is given by

$$
\frac{\dot{E}}{E}=r-\rho
$$

i.e. nominal consumption spending grows at a rate equal to the difference between the interest rate and the subjective rate of time preference.

\subsection{Product market}

Three types of firms produce goods: Northern firms $(N)$, Northern multinationals $(M)$, and Southern imitators $(S)$. Denote firms by $J$ where $J=N$, $M$, or $S$. Northern firms can either produce in the North or the South. A firm needs one worker to produce a unit of output in the North, whereas $\theta \geq 1$ workers per unit of output are needed in the South. Intuitively, this is due to the costs of coordinating decisions over large distances and operating in unfamiliar foreign environments. Indeed, the theory of the multinational enterprise argues that such firms rely on 'ownership' advantages derived from technological assets and/or brand names in order to offset the disadvantages they face relative to local firms (see Markusen, 1995).

Given the constant elasticity demand functions, it is straightforward to show that prices of Northern firms are mark-ups over their marginal costs:

$$
p^{N}=\frac{w^{N}}{\alpha} \text { and } p^{M}=\frac{\theta w^{S}}{\alpha}
$$

Southern firms can produce only those goods that they have successfully imitated and they need one worker to produce one unit of output. If successful in imitating a multinational, a Southern firm charges its optimal monopoly price

$$
p^{S}=\frac{w^{S}}{\alpha}
$$

Note that this price can be sustained if and only if it lies below the multinational's marginal cost $\theta w^{S}$ :

$$
\frac{w^{S}}{\alpha}<\theta w^{S} \Leftrightarrow \theta \alpha>1 .
$$


In what follows, we assume $\theta \alpha>1 .^{9}$

Let $x^{J}$ denote the output level of firm $J$ where $J=N, M$, or $S$. We know from the demand functions that

$$
\frac{x(i)}{x(j)}=\frac{p_{i}^{-\varepsilon}}{p_{j}^{-\varepsilon}}
$$

Using the pricing equations for the three types of products, we have

$$
\frac{x^{S}}{x^{M}}=\theta^{\varepsilon}
$$

and

$$
\frac{x^{M}}{x^{N}}=\left[\frac{\theta w^{S} / \alpha}{w^{N} / \alpha}\right]^{-\varepsilon}=\left[\frac{\theta w^{S}}{w^{N}}\right]^{-\varepsilon} \text { and } \frac{x^{S}}{x^{N}}=\left[\frac{w^{S}}{w^{N}}\right]^{-\varepsilon}
$$

Flow profit of a Northern producer is given by

$$
\pi^{N}=\left(p^{N}-w^{N}\right) x^{N}=\frac{(1-\alpha) w^{N} x^{N}}{\alpha}
$$

Similarly, a multinational's flow profit equals

$$
\pi^{M}=\left(p^{M}-w^{S}\right) x^{M}=\frac{\theta(1-\alpha) w^{S} x^{M}}{\alpha}
$$

while that of a Southern firm equals

$$
\pi^{S}=\left(p^{S}-w^{S}\right) x^{S}=\frac{(1-\alpha) w^{S} x^{S}}{\alpha}
$$

\section{$2.2 \quad$ FDI and Imitation}

Of the $n$ goods that exist, $n_{N}$ are produced in the North, $n_{M}$ are produced in the South by Northern multinationals, and $n_{I}$ are produced by Southern imitators. Let $n_{S} \equiv n_{I}+n_{M}$ denote all goods produced in the South. In what follows, we will think of the level of Southern industrial development as roughly corresponding to the Southern share of global manufacturing; i.e., the ratio of goods produced in the South to the number of goods that exist at a point in time. Since this measure of industrial development explicitly

\footnotetext{
${ }^{9}$ When $\theta \alpha<1$, a Southern imitator limit prices the Northern firm whose product it has copied by setting its price equal to the Northern firm's marginal cost $\theta w^{S}$.
} 
includes the activities of affiliates of Northern multinationals, the advance of Southern industrial development in our model depends on the rate of FDI.

Let the rate of imitation $\mu$ be defined by

$$
\mu \equiv \frac{\dot{n_{I}}}{n_{M}}
$$

i.e. $\mu$ denotes the rate of increase of the stock of imitated goods relative to the total number of goods produced by Northern multinationals. Since both multinationals and Southern imitators produce in the South, imitation simply transfers ownership of a good (and the associated flow of profits) from the hands of a multinational to a Southern imitator.

The rate of North-South FDI is defined by

$$
\phi \equiv \frac{\dot{n_{S}}}{n_{N}}
$$

where $n_{N}$ denotes the number of goods produced in the North. In other words, at each instant, the the total stock of goods produced in the South increases by $\phi n_{N}$. Note that this measures the inflow of North-South FDI because imitation only targets Northern multinationals and does not, by itself, lead to North-South production shifting.

Like Grossman and Helpman (1991b) and Lai (1998), we study a steady state equilibrium in which prices, nominal spending, and all product categories grow at the same rate $g$ :

$$
g \equiv \frac{\dot{n}}{n}=\frac{\dot{n_{N}}}{n_{N}}=\frac{\dot{n_{I}}}{n_{I}}=\frac{\dot{n_{M}}}{n_{M}}=\frac{\dot{n_{S}}}{n_{S}}=\frac{\dot{E}}{E}
$$

To facilitate exposition, we initially analyze our model under the assumption that the rate of innovation $g$ is exogenously given and then in Section 4 analyze the fully endogenous model.

Equations (6), and (14) through (15) imply that in steady state the interest rate equals the sum of the subjective discount rate and the growth rate:

$$
r=\rho+g
$$

Furthermore, the steady state allocation of products across the two regions satisfies

$$
\frac{n_{N}}{n}=\frac{g}{g+\phi} \text { and } \frac{n_{S}}{n_{N}}=\frac{\phi}{g}
$$


Similarly, the ratio of multinationals to their two types of competitors equals

$$
\frac{n_{M}}{n_{N}}=\frac{\phi}{g+\mu} \text { and } \frac{n_{M}}{n_{I}}=\frac{g}{\mu}
$$

The lifetime value of a Northern firm that opts to produce in the North equals:

$$
v^{N}=\frac{\pi^{N}}{\rho+g}
$$

Note from above that since future products creates competition for existing products, an increase in the rate of innovation $(g)$ reduces the life-time value of a Northern firm.

While it is cheaper to produce in the South (as we show below, the Southern relative wage is lower in equilibrium), shifting production to the South invites the risk of imitation and the value of a Northern multinational firm equals

$$
v^{M}=\frac{\pi^{M}}{\rho+\mu+g}
$$

As is clear, in calculating the value of a multinational firm, the flow profit $\pi^{M}$ is discounted not just by the effective interest rate (which equals $\rho+$ $g$ ) but also by the rate of imitation $\mu$. As in Lai (1998), we assume that imitation targets only Northern multinationals. In other words, the risk faced by Northern firms that refrain from shifting production to the South has been normalized to zero. In reality, Northern firms that do not undertake FDI can also have their technologies imitated, but the risk of imitation they face is probably lower than that of multinational firms that produce in the South. As is known from the work of Mansfield (1994) and Maskus (2000), multinational firms indeed internalize the risk of imitation that they face due to weak IPR protection in host countries. ${ }^{10}$

Finally, the lifetime value of a Southern producer (i.e. the reward earned by a successful imitator) equals

$$
v^{S}=\frac{\pi^{S}}{\rho+g}
$$

\footnotetext{
${ }^{10}$ Our core results would still hold if the risk of imitation of Northern firms were set at some constant rate greater than zero but less than that faced by multinational firms.
} 


\subsection{Relative wage}

Since all Northern firms have the option of becoming multinationals, we must have $v^{N}=v^{M}$ which implies

$$
\frac{\pi^{M}}{\pi^{N}}=1+\frac{\mu}{\rho+g}
$$

Note immediately from above that if the risk of imitation is positive (i.e. $\mu>$ 0 ) then we must have $\pi^{M}>\pi^{N}$. This is intuitive: since any Northern firm is free to become a multinational, the flow profit earned by a multinational must be higher in order to compensate for the risk of imitation faced (only) by multinationals. ${ }^{11}$

From the definition of profit we have

$$
\frac{\pi^{M}}{\pi^{N}}=\frac{\theta w^{S} x^{M}}{w^{N} x^{N}}=\left[\frac{\theta w^{S}}{w^{N}}\right]^{1-\varepsilon}
$$

The last two equations allow us to write the Northern relative wage $\left(w^{R}\right)$ as a function of the rate of innovation and imitation as well as some of the exogenous parameters of the model:

$$
w^{R} \equiv \frac{w^{N}}{w^{S}}=\theta\left[1+\frac{\mu}{\rho+g}\right]^{\frac{1}{\varepsilon-1}}
$$

As is clear, the relative wage in the North increases with the production disadvantage faced by Northern multinationals $(\theta)$ as well as with the Southern rate of imitation $(\mu)$ since both of these factors discourage Northern firms from relocating production to the South. This reluctance to shift production to the South increases the relative demand for Northern labor and therefore North's relative wage. As we noted earlier, this result differs from that of Grossman and Helpman (1991b) and is line with Lai (1998). Why do these models yield such different results regarding the determinants of the NorthSouth relative wage? In Grossman and Helpman (1991b), Southern imitation of firms producing in the North serves as the channel through which international reallocation of production (and therefore labor demand) occurs. By

\footnotetext{
${ }^{11}$ Indeed, since prices of Northern firms and multinationals are marked up over their respective marginal costs by the same amount (i.e. $1 / \alpha$ ) the relative sales of a typical multinational must exceed that of a Northern firm: $\frac{p^{M} x^{M}}{p^{N} x^{N}}=1+\frac{\mu}{\rho+g}$.
} 
contrast, in our model as well as in Lai (1998) Southern imitation targets multinational firms and North-South FDI is the channel of international reallocation of production. In our model, by lowering the risk of imitation, a strengthening of Southern IPR protection increases FDI and the demand for Southern labor while it reduces demand for Northern labor. In Grossman and Helpman (1991b), the opposite happens: as imitation declines, more production stays in the North and less of it occurs in the South. Hence the North-South relative wage behaves rather differently across these models.

\subsection{Imitation incentives and Southern IPR protection}

At any given point in time, the unit labor requirement in imitation is given by $\frac{a_{I}}{n_{S}}$. In other words, the unit labor requirement in imitation is assumed to decline with the number of goods produced in the South $\left(n_{S}=n_{I}+n_{M}\right)$. The idea underlying this formulation is that imitation and Northern FDI generate knowledge spillovers for the South that lower the cost of imitation over time. This decline in imitation cost is necessary to sustain imitation in the long run since an ongoing expansion in the number of products in the global economy reduces the profitability of imitation over time.

We consider two different formulations of Southern IPR protection. Under our first formulation, the cost function for imitation is given by

$$
c_{I}=\frac{k a_{I} w^{S}}{n_{S}}
$$

where $k \geq 1$ is an index of the degree of IPR protection in the South. The idea underlying this formulation is that as IPR protection is strengthened, imitation becomes a more costly activity for Southern firms because evading local enforcement of IPRs becomes more difficult. Under our second formulation, the cost function of imitation is given $c_{I}=\frac{a_{I} w^{S}}{n_{S}}$ and a Southern imitator's flow profit equal $\pi_{k}^{S}=(1-k) \pi^{S}=(1-k)(\theta-1) w^{S} x^{S}$ where $0 \leq k \leq 1$. Under this formulation, IPR policy is akin to a profit tax on imitators: the more stringent is IPR protection, the smaller the rents from imitation. Alternatively, one could view $k \pi^{S}$ as the share of its profit stream that an imitator must surrender to local authorities for them to willingly turn a blind eye towards the violation of IPRs of Northern multinationals.

Free entry into imitation implies that the reward from imitation should 
equal its cost:

$$
v^{S}=\frac{k a_{I} w^{S}}{n_{S}} \Leftrightarrow \frac{\pi^{S}}{\rho+g}=\frac{k a_{I} w^{S}}{n_{S}}
$$

Substituting from (12) into the above equation and using (8) gives the sales levels of a Southern imitator and a Northern multinational:

$$
x^{S}=\frac{\alpha}{1-\alpha} \frac{k a_{I}(\rho+g)}{n_{S}} \text { and } x^{M}=\frac{\alpha}{1-\alpha} \frac{k a_{I}(\rho+g)}{n_{S} \theta^{\varepsilon}}
$$

Furthermore, using

$$
\frac{x^{N}}{x^{S}}=\left[w^{R}\right]^{-\varepsilon}
$$

we have

$$
x^{N}=\frac{\alpha}{1-\alpha} \frac{k a_{I}(\rho+g) A(\mu, g)}{n_{S} \theta^{\varepsilon}}
$$

where

$$
A(\mu, g) \equiv\left[\frac{\rho+g}{\rho+g+\mu}\right]^{\frac{1}{\alpha}}<1 .
$$

The following lemma reports some important properties of the function $A(\mu, g)$.

Lemma 1: $A(\mu, g)<1$ and $\frac{\partial A(\mu, g)}{\partial \mu}<0<\frac{\partial A(\mu, g)}{\partial g}$.

\subsection{General equilibrium}

The conditions for general equilibrium are derived from the resource constraints in the two regions. In the North, when the rate of innovation is exogenously given, all labor is allocated to production. Let $L_{d}^{i}$ denote aggregate labor demand in region $i$ where $i=N, S$. Then $L_{d}^{N} \equiv n_{N} x^{N}$. Substituting from (16) and (26) allows us to write aggregate labor demand in the North as

$$
L_{d}^{N} \equiv \frac{g}{\phi} \frac{\alpha}{1-\alpha} \frac{k a_{I}(\rho+g) A(\mu, g)}{\theta^{\varepsilon}}
$$

which implies that the Northern labor market equilibrium condition is given by

$$
\frac{g}{\phi} \frac{\alpha}{1-\alpha} \frac{k a_{I}(\rho+g) A(\mu, g)}{\theta^{\varepsilon}}=L^{N}
$$


It is obvious from (27) that aggregate labor demand in the North $L_{d}^{N}$ decreases in $\phi$. Furthermore, Lemma 1 implies that $L_{d}^{N}$ decreases in $\mu$. These two properties of $L_{d}^{N}$ imply that in the $(\phi, \mu)$ space, the Northern labor market equilibrium condition, which we will refer to as the $N N$ curve, is downward sloping: $\left.\sigma^{N}(\phi, \mu) \equiv \frac{d \mu}{d \phi}\right|_{L_{d}^{N}=L^{N}}=-\frac{\alpha(\rho+\mu+g)}{\phi}<0$. Note the following properties of $\sigma^{N}(\phi, \mu):(i)$ it is independent of the IPR index $k ;(i i)$ increases in $\mu$ while it decreases in $\phi$ and (iii) is undefined for $\phi=0$. Property (ii) implies that the $N N$ curve is convex in the $(\phi, \mu)$ space whereas property (iii) implies that it does not intersect the vertical axis. From (27) it is straightforward that the $N N$ curve intersects the horizontal axis at $\phi_{0}$ where $\phi_{0}=\frac{g}{L^{N}} \frac{\alpha}{1-\alpha} \frac{k a_{I}(\rho+g)}{\theta^{\varepsilon}}>0$.

Southern labor is allocated to imitation and production by multinationals and local firms. Therefore we must have :

$$
L_{d}^{S} \equiv \frac{k a_{I}}{n_{S}} \dot{n}_{I}+\theta n_{M} x^{M}+n_{I} x^{S}=L^{S}
$$

Substituting into the above resource constraint from equations (16), (17), and (24) gives

$$
k a_{I} \frac{g \mu}{g+\mu}+\frac{\theta \alpha k a_{I}(\rho+g)}{\theta^{\varepsilon}(1-\alpha)} \frac{g}{g+\mu}+\frac{\alpha k a_{I}(\rho+g)}{1-\alpha} \frac{\mu}{g+\mu}=L^{S}
$$

Observe from (30) that, in steady state, labor demand in the South is independent of the flow of North-South FDI $\phi$. This implies that in the $(\phi, \mu)$ space, the Southern labor market equilibrium condition (called the $S S$ curve) is a horizontal line at the equilibrium rate of imitation - i.e. $\left.\sigma^{S}(\phi, \mu) \equiv \frac{d \mu}{d \phi}\right|_{L_{d}^{S}=L^{S}}=0 .{ }^{12}$

The equilibrium allocation of resources in the global economy is given by the intersection of the $N N$ and $S S$ curves.

\section{Effects of Southern IPR protection}

In this section, we study the effects of a strengthening of Southern IPR protection when the rate of innovation $(g)$ is exogenously given. We begin by

\footnotetext{
${ }^{12}$ The explicit formula for the equilibrium rate of imitation with $g$ exogenous is reported in the appendix.
} 
establishing some crucial properties of the North-South flow of FDI. Solving equation (27) for FDI flow $\phi$ in terms of the rate of imitation $(\mu)$ gives

$$
\phi=\frac{\alpha}{1-\alpha} \frac{g}{L^{N}} \frac{k a_{I}(\rho+g) A(\mu, g)}{\theta^{\varepsilon}}
$$

Observe immediately from (31) that holding $\mu$ constant the numerator of the right hand side increases with $g$ : recall from Lemma 1 that $A(\mu, g)$ increases with $g$. Due to the same reason, the ratio $\phi / g$ also increases in $g$. This implies the following:

Remark 1: Holding constant the rate of imitation ( $\mu)$, the flow of FDI $(\phi)$ to the South increases with the rate of Northern innovation: $\frac{\partial \phi}{\partial g}>0$. Furthermore, the elasticity of the flow of FDI with respect to the rate of innovation is greater than unity: $\frac{g}{\phi} \frac{\partial \phi}{\partial g}>1$.

In this context, it is worth noting that a large number of empirical studies have demonstrated a strong positive correlation between innovation and FDI and, as Markusen (1995) notes, this finding is so pervasive that it has become a cornerstone of the modern theory of the multinational firm.

Suppose now that the South increases the degree of IPR protection $(k)$ available to Northern firms. Note first that equation (30) can be written as

$$
L_{d}^{S}(\phi, \mu)=a_{I} \frac{g \mu}{g+\mu}+\frac{\theta \alpha a_{I}}{1-\alpha} \frac{g(\rho+g)}{\theta^{\varepsilon}(g+\mu)}+\frac{\alpha a_{I}}{1-\alpha} \frac{\mu(\rho+g)}{g+\mu}=\frac{L^{S}}{k}
$$

In other words, from the viewpoint of the South, holding constant the rates of imitation $(\mu)$ and innovation $(g)$, an increase in the degree of IPR protection $(k)$ is an effective reduction in the real resources available (i.e. a decline in $\frac{L^{S}}{k}$ ) since all three activities that the South is engaged in - imitation, production by multinational firms, and production by local imitators - would require more resources if $k$ increases and $\mu$ remains unchanged. It is intuitively obvious why an increase in the cost of imitation increases the resources required to sustain a given level of imitation. But why do the two production activities undertaken in the South also become more resource intensive with an increase in the IPR index $k$ ? The intuition for this comes from the free entry condition in imitation: as the cost of imitation increases, the sales of a firm that is successful in imitation also must increase in order to maintain the zero profit condition in imitation. Finally, the sales of a 
multinational $\left(x^{M}\right)$ are proportional to the sales of a Southern imitator $\left(x^{M}\right)$ and if $x^{S}$ increases, so must $x^{M}$.

Direct calculations yield

$$
\frac{\partial L_{d}^{S}}{\partial \mu}=\frac{k a_{I}\left[\theta^{\varepsilon}(g+\alpha \rho)-\alpha \theta(\rho+g)\right]}{(\mu+g)^{2}(1-\alpha) \theta^{\varepsilon}}>0
$$

because $\theta^{\varepsilon}>\theta$ and $\alpha<1$. Since aggregate labor demand in the South $L_{d}^{S}$ increases with the rate of imitation $\mu$ and the effective labor supply $\left(\frac{L^{S}}{k}\right)$ falls with the Southern IPR index $k$, the rate of imitation $\mu$ must fall with $k$ or else the Southern labor market would fail to clear.

Now consider how an increase in $k$ effects the $N N$ curve. Since the slope of this curve $\sigma^{N}(\phi, \mu)$ is independent of $k$ whereas the horizontal intercept $\phi_{0}$ increases with $k$, the $N N$ curve shifts outward with an increase in $k$. The decline in the rate of imitation (i.e. the downward shift in the $S S$ curve) along with the outward shift in the $N N$ curve yields:

Proposition 1: When the rate of innovation $(g)$ is exogenously given, a strengthening of Southern IPR protection lowers the rate of Southern imitation $(\mu)$ and it increases the rate of North-South FDI $(\phi): \frac{d \mu}{d k}<0<\frac{d \phi}{d k}$.

The logic behind Proposition 1 is easy to see. Recall from Lemma 1 that $A(\mu, g)$ decreases in $\mu$. Since $\mu$ decreases in $k$, it follows then that $k A(\mu, g)$ increases in $k$. But with $g$ fixed, equation (27) also implies that the North-South flow of FDI $\phi$ necessarily increases with $k$ or else the Northern labor market cannot clear. Figure 1 illustrates Proposition 1 in the $(\phi, \mu)$ space. ${ }^{13}$ With a strengthening of Southern IPR protection, the $S S$ curve shifts down while the $N N$ curve shifts up and the equilibrium of the world economy moves from point $A$ to $B$, where the rate of Southern imitation is lower whereas the rate of North-South FDI is higher.

\footnotetext{
${ }^{13}$ The following parameters were used to generate Figure 1: $L^{S}=200, L^{N}=450$, $a_{N}=1, \rho=1 / 10, \theta=2$, and $\alpha=1 / 2$. The unit labor requirement in imitation $k \cdot a_{I}$ was increased from 0.66 to 0.7 .
} 


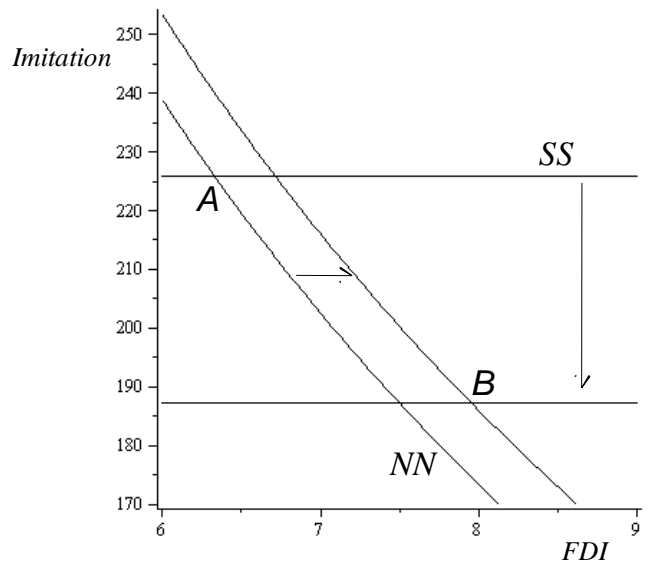

Figure 1: Effects of an increase in Southern IPR protection on imitation and FDI

Since Proposition 1 is our core result from which most other results are derived, it is worth checking whether it holds when Southern IPR protection determines how much rent local imitators collect from their investment in imitation as opposed to making imitation more costly. Let a Southern imitator's flow profit from imitation equal $\pi_{k}^{S}=(1-k) \pi^{S}=\frac{(1-k)(1-\alpha) w^{S} x^{S}}{\alpha}$ where $k$ measures the degree of IPR protection and $0 \leq k \leq 1$. It is straightforward that in the Northern labor market equilibrium condition (27) we simply need to replace $1 / k$ by $(1-k)$ whereas in the Southern labor market equilibrium condition (30) the same substitution is needed in the second and third terms of the LHS; in the first term of the same equation, $k$ needs to be simply replaced by 1 . Since an increase in $k$ in our profit tax based formulation of IPR protection has analogous effects to an in increase in $k$ under our cost based formulation, Proposition 1 holds under both formulations.

\subsection{Southern industrial development and FDI}

An important objective of this paper is to understand how a strengthening of IPR protection in the South alters the distribution of production across the two regions as well as between Northern multinationals and Southern imitators. How Southern IPR protection affects the global allocation of production depends on its effects on Southern imitation and the North-South flow of FDI. To see the effect of an increase in $k$ on the international allocation of production, first note that $\frac{n_{S}}{n}=\frac{\phi}{\phi+g}$. Since $\phi$ increases in $k$ and $g$ is 
exogenously fixed we must have:

Corollary 1 (Inter-regional Reallocation of Production): A strengthening of Southern IPR protection increases the South's share of the total basket of goods produced in the global economy $\left(\frac{n_{S}}{n}\right): \frac{d\left(n_{S} / n\right)}{d k}>0$.

Given that $\frac{n_{I}}{n_{M}}=\frac{\mu}{g}$ decreases with $k$, we can state the following result regarding the allocation of production within the South between multinationals and Southern firms:

Corollary 2 (Intra-regional Reallocation of Production): A strengthening of Southern IPR protection increases the share of Southern production undertaken by Northern multinational firms $\left(\frac{n_{M}}{n_{S}}\right): \frac{d\left(n_{M} / n_{S}\right)}{d k}>0$.

It is straightforward to show that the total value of multinational sales relative to those of Southern imitators has the following simple expression:

$$
\frac{n_{M} p^{M} x^{M}}{n_{I} p^{S} x^{S}}=\frac{g}{\theta^{\varepsilon-1} \mu}
$$

Since the the rate of imitation $(\mu)$ falls with an increase in the degree of Southern IPR protection, it implies that a strengthening of Southern IPR protection leads to an increase in the aggregate sales of multinational firms relative to those of Southern imitators.

Now consider a comparison of total multinational sales relative to those of firms producing in the North:

$$
\frac{n_{M} p^{M} x^{M}}{n_{N} p^{N} x^{N}}=\frac{\phi}{g+\mu}\left[\frac{\theta w^{S}}{w^{N}}\right]^{1-\varepsilon}=\frac{\phi}{g+\mu}\left[1+\frac{\mu}{\rho+g}\right]
$$

Since $\frac{n_{M}}{n_{N}}=\frac{\phi}{g+\mu}$, equation (33) implies that a typical multinational must have higher relative sales compared to a Northern firm (i.e. the ratio $p^{M} x^{M} / p^{N} x^{N}$ must exceed 1). Intuitively, since imitation only targets multinational firms, for a typical multinational to earn the same rate of return as a Northern firm producing in the North, the multinational must have a higher relative profit flow. However, with a decline in the rate of imitation, this relative profit flow actually has to shrink in order to ensure multinationals and Northern firms earn the same rate of return. In other words, a strengthening of Southern 
IPR protection decreases the sales of a typical multinational firm relative to those of a Northern firm.

In this context, one further subtlety that arises from general equilibrium considerations is worth noting: an decrease in the rate of imitation $\mu$ increases the relative Southern wage and therefore the cost of production of multinationals relative to Northern firms. However, since prices of both types of firms are mark-ups over their respective marginal costs, this cost increase has a proportional effect on prices of multinationals relative to those of Northern firms. In other words, by increasing the South's relative wage, IPR reform increases the prices charged by multinationals relative to those of Northern firms and this translates into lower relative sales for a typical multinational.

\subsection{Real wages and the aggregate price index}

What are the effects of a strengthening of IPR protection in the South on real wages in the two regions? By definition, the real wage effects of such a policy change depends upon nominal wages in the two regions and the prices of goods produced by three types of firm: firms located in the North, multinationals producing in the South, and Southern imitators. Recall that

$$
p^{N}=\frac{w^{N}}{\alpha} ; p^{M}=\frac{\theta w^{S}}{\alpha} ; \text { and } p^{S}=\frac{w^{S}}{\alpha}
$$

which allows us to write Northern real wages in terms of the three types of goods:

$$
\frac{w^{N}}{p^{N}}=\alpha ; \frac{w^{N}}{p^{M}}=\frac{\alpha}{\theta} w^{R} ; \frac{w^{N}}{p^{S}}=\alpha w^{R}
$$

In other words, the Northern real wage in terms of goods produced by Northern firms is unaffected by Southern IPR protection whereas in terms of the other two goods, it moves in the same direction as the Northern relative wage $w^{R}$. We already know that Northern relative wage decreases as a result a strengthening of Southern IPR protection since the rate of imitation $\mu$ falls with such a policy change. This decline in the Northern relative wage $w^{R}$ implies that a strengthening of Southern IPR protection decreases real wages in the North. 
Consider now the effect on Southern real wages. We have

$$
\frac{w^{S}}{p^{S}}=\alpha ; \frac{w^{S}}{p^{N}}=\frac{\alpha}{w^{R}} ; \text { and } \frac{w^{S}}{p^{M}}=\frac{\alpha}{\theta}
$$

In other words, the only effect on Southern real wages of a change in its IPR policy is in terms of goods produced in the North. However, since $w^{R}$ decreases with $\mu$, it implies that a strengthening of Southern IPR protection increases real wages in the South. The general equilibrium nature of this result deserves emphasis. A common argument in favor of weaker IPR protection in the South is that Southern imitation lowers prices and therefore benefits consumers. Since prices of Southern imitators are lower than those of Northern multinationals, this channel is operative in our model as well. However, the story does not end there: international production shifting that results from a reduction in the rate of imitation also has labor market effects. In our model, a strengthening of Southern IPR protection leads to a higher Southern relative wage since the resulting decline in imitation risk makes the South a more attractive location for Northern multinationals. Indeed, changes in prices are dominated by the change in the Southern relative wage so that the purchasing power of Southern workers in terms of goods produced in the North increases whereas there is no change in their ability to purchase goods produced in the South.

Despite an increase in real wages, Southern welfare does not necessarily increase because the flow of utility equals the log of real spending $(\log u=\log$ $E-\log P$ ) and a reduction in profits of Southern imitators lowers Southern income and can adversely impact Southern spending. While a complete welfare analysis along the lines of Helpman (1993) is beyond the scope of the paper, it is useful to consider how a strengthening of Southern IPR protection affects the aggregate price index $P$. By definition,

$$
P=\left[\int_{0}^{n} p(j)^{1-\varepsilon} d j\right]^{\frac{1}{1-\varepsilon}}
$$

which can be rewritten as

$$
P=\left[n_{M}\left(p^{M}\right)^{1-\varepsilon}+n_{I}\left(p^{S}\right)^{1-\varepsilon}+n_{N}\left(p^{N}\right)^{1-\varepsilon}\right]^{\frac{1}{1-\varepsilon}}
$$

which is the same as

$$
P=n^{\frac{1}{1-\varepsilon}}\left[\frac{n_{M}}{n}\left(p^{M}\right)^{1-\varepsilon}+\frac{n_{I}}{n}\left(p^{S}\right)^{1-\varepsilon}+\frac{n_{N}}{n}\left(p^{N}\right)^{1-\varepsilon}\right]^{\frac{1}{1-\varepsilon}}
$$


While goods produced by multinationals are cheaper than those produced by Northern firms $\left(p^{M}<p^{N}\right)$, it is the Southern imitators that produce the cheapest goods $\left(p^{S}<p^{M}\right)$. Recall that $\frac{n_{I}}{n_{M}}=\frac{\mu}{g}$ decreases with the degree of Southern IPR protection $(k)$ since imitation slows down while innovation increases. This implies that $\frac{n_{I} / n}{n_{M} / n}=\frac{\mu}{g}$ decreases with $k$, i.e., the share of global production that is in the hands of multinational firms increases. Furthermore, recall that a strengthening of Southern IPR protection shifts production away from the North and towards the South (inter-regional reallocation). Since $p^{M}<p^{N}$, the inter-regional reallocation of production from North to the South helps lower the overall price index. However, since $p^{M}>p^{S}$, the intra-regional reallocation of Southern production in favor of Northern multinationals and away from Southern imitators has the opposite effect. This implies that if the inter-regional reallocation of production is substantial, Southern imitation has the potential to partially benefit Northern consumers by lowering the aggregate price index $P$. Indeed, this is the key reason why Helpman (1993) finds that some amount of imitation is in the interest of the North. However, in our model, since FDI also offers the potential for lowering prices, imitation is not as crucial for welfare purposes. This is worth explaining in some detail. Unlike us, Helpman (1993) assumes that the risk of imitation applies equally to Northern firms and multinationals. As a result, multinationals and Northern producers can coexist in equilibrium only if the two regions have equal wages. ${ }^{14}$ Under such wage equalization, FDI offers no reduction in costs of production and therefore has no price effects. By contrast, in our model, both FDI and imitation imply cost savings and the allocation of production across regions as well as within the South have implications for the aggregate price index.

We next study the effects of a strengthening of Southern IPR protection when innovation is endogenous.

\footnotetext{
${ }^{14}$ Our model would yield the same result if the rate of imitation facing multinationals and Northern producers were the same (i.e. $\mu=0$ ) and multinationals did not face any frictions that hamper their ability to be as effective in production as local Southern firms (i.e. $\theta=1$ ).
} 


\section{The model with endogenous innovation}

Note first that when the rate of innovation is endogenously determined, the results obtained under the assumption of exogenous innovation (i.e. Proposition 1 and Corollaries 1-2) continue to hold so long as a strengthening of Southern IPR protection does not decrease the Northern rate of innovation g. In what follows, we show that an increase in the Southern IPR protection index $k$ actually increases the rate of innovation (Proposition 2). In addition, we also show that an increase in R\&D productivity of the North increases both innovation and North-South FDI (Proposition 3) and that a policy of attracting multinational firms through a reduction in the profit tax imposed on them has effects quite similar to a strengthening of Southern IPR protection.

\subsection{Costly innovation}

When innovation is endogenous and there is free entry into it, the value of a Northern firm must exactly equal the cost of innovation:

$$
v^{N}=\frac{w^{N} a_{N}}{n} \Leftrightarrow \frac{\pi^{N}}{\rho+g}=\frac{w^{N} a_{N}}{n}
$$

where $a_{N}$ is the unit labor requirement in innovation and $\frac{w^{N} a_{N}}{n}$ measures the up-front cost of product development. This formulation assumes that the cost of designing new products falls with the number of products $(n)$ that have been invented. In other words, knowledge spillovers from innovation sustain further innovation. This assumption is standard in the literature (see Grossman and Helpman, 1991a and b, and Romer, 1990) and in its absence growth cannot be sustained in the variety expansion model with fixed resources. This is because the flow profit of a successful innovator declines with the number of products invented and incentives for innovation disappear in the long run if the cost of innovation does not also fall with an increase in the number of products.

Substituting from equation (10) into (34) gives the output level of a Northern firm

$$
x^{N}=\frac{\alpha}{1-\alpha} \frac{a_{N}(\rho+g)}{n}
$$


From equations (34) and (23) we have

$$
\frac{n}{n_{S}} \frac{k a_{I}}{a_{N}} \frac{v^{N}}{v^{S}} \frac{w^{S}}{w^{N}}=1
$$

Utilizing the definition of firm values and profits allows us to rewrite the above equation as

$$
\frac{n}{n_{S}} \frac{k a_{I}}{a_{N}} \frac{\frac{\pi^{N}}{\rho+g}}{\frac{\pi^{S}}{\rho+g}} \frac{w^{S}}{w^{N}}=1 \Leftrightarrow \frac{n}{n_{S}} \frac{k a_{I}}{a_{N}} \frac{x^{N}}{x^{S}}=1
$$

Using equations (9) and (21) the above equation becomes

$$
\frac{n_{S}}{n} \frac{a_{N} \theta^{\varepsilon}}{k a_{I}}\left[1+\frac{\mu}{\rho+g}\right]^{\frac{\varepsilon}{\varepsilon-1}}=1
$$

Substituting from (16) and (17) into the above equation gives us an equilibrium relationship between the three endogenous variables $g, \phi$, and $\mu$ and the exogenous parameters of the model:

$$
\frac{\phi}{\phi+g} \frac{\theta^{\varepsilon} a_{N}}{k a_{I}}\left[1+\frac{\mu}{\rho+g}\right]^{\frac{\varepsilon}{\varepsilon-1}}=1
$$

Intuitively, this condition follows from the assumption of free entry into imitation and innovation and it ensures that neither activity leads to excess profits for firms that are successful in such activities.

Solving equation (39) for FDI flow $\phi$ in terms of the other two endogenous variables $(g$ and $\mu$ ) gives

$$
\phi=\frac{g}{\frac{\theta^{\varepsilon} a_{N}}{A(\mu, g) k a_{I}}-1}
$$

Observe immediately from (40) that holding $\mu$ constant the denominator of the right hand side increases with $g$ : this is because $\mu / g$ falls with $g$ whereas $A(\mu, g)$ increases (Lemma 1). This implies the following result:

Remark 2: Holding constant the rate of imitation ( $\mu)$, factors that increase the North-South flow of FDI ( $\phi)$ must also increase the rate of Northern innovation $(g)$.

Since both innovation and FDI are endogenous, Remark 2 notes that the flow of FDI and the rate of innovation are positively related in our model. 
In this context, it is worth noting that a large number of empirical studies have demonstrated that there is a positive correlation between innovation and FDI; as Markusen (1995) notes, this finding is so pervasive that it has become a cornerstone of the modern theory of the multinational firm. Furthermore, since $A(\mu, g)$ decreases with $\mu$, we have:

Remark 3: Holding constant the rate of innovation ( $g$ ), factors that decrease the Southern rate of imitation ( $\mu$ ) must also increase the NorthSouth flow of FDI ( $\phi)$.

An important point to note is that since our model exhibits a negative feedback between FDI and imitation and a positive feedback between FDI and innovation, it necessarily implies a negative feedback between innovation and imitation. This is an important property of the model which differentiates it from the results of Grossman and Helpman (1991b) and aligns it with those of Lai (1998).

Consider now the direct effect of Southern IPR protection on the NorthSouth flow of FDI. From (40) directly observe that the denominator in the formula of $\phi(\mu, g)$ decreases with $k$ so that we have:

Remark 4: Holding constant the rates of imitation ( $\mu)$ and innovation $(g)$, the flow of FDI ( $\phi)$ to the South increases with a strengthening of Southern IPR protection (i.e. an increase in $k$ ).

The intuition for this result comes from equation (38) which requires the rate of return on innovation and imitation to equal each other. Since the right hand side of this equation always equals 1 , an increase in the IPR index $k$ must be counterbalanced by an increase in the ratio of production $\left(\frac{n_{S}}{n}=\frac{\phi}{\phi+g}\right)$ that occurs in the South for the cost of imitation to not increase relative to the cost of innovation which in turn requires that the flow of FDI $\phi$ increases with the degree of IPR protection $k$.

It is well-known that multinational firms conduct a large share of global research and development $(\mathrm{R} \& \mathrm{D})$. Indeed, a generation of empirical studies have documented the positive correlation between FDI flows and R\&D investment (Markusen, 1995). Given this, it is worth noting from equation (40) that, holding constant the rate of innovation and imitation, an increase 
in the R\&D productivity of Northern firms (as measured by an decrease in $a_{N}$ ) implies a faster North-South flow of FDI. We later discuss the general equilibrium response of FDI to an increase in Northern R\&D productivity taking into account its effects on the rates of imitation and innovation.

\subsection{Southern IPR protection under endogenous inno- vation}

Assuming the rate of imitation is exogenously given, Lai (1998) has shown that a decline in this rate increases Northern innovation and the rate of production shifting to the South. ${ }^{15}$ A crucial question is whether this important result holds when both imitation and innovation are endogenous and the underlying exogenous variable is the degree of IPR protection (i.e. parameter $k$ ). Under endogenous innovation, the Southern labor market equilibrium condition (30) remains unaltered where in the North we now need to account for resources allocated to innovation:

$$
\frac{a_{N}}{n} \dot{n}+n_{N} x^{N}=L^{N}
$$

Substituting into the above resource constraint from the market measure equations (16), (17), and (35) yields

$$
a_{N} g+\frac{g}{g+\phi} \frac{a_{N} \alpha(\rho+g)}{(1-\alpha)}=L^{N}
$$

Equations (30), (39), and (42) define the steady state equilibrium of the model in terms of the three endogenous variables: the rate of innovation $g$, the rate of imitation $\mu$, and the rate of FDI $\phi$. All of the effects of increased IPR protection in the South (i.e. an increase in $k$ ) are derived from the effects on these endogenous variables. Using the equilibrium flow of FDI and the two resource constraints, we can derive a system of two equations in two unknowns that helps provide a graphical illustration of the consequences of stronger IPR protection in the South.

Recall that the Southern labor market constraint is independent of the flow of FDI $\phi$. As before, let $L_{d}^{S}$ measure aggregate labor demand in the South (given by the LHS of equation (30)). Recall that $\frac{\partial L_{d}^{S}}{\partial \mu}>0$ - i.e.

\footnotetext{
${ }^{15}$ In the appendix, we show how our model relates to Lai (1998).
} 
holding constant the rate of innovation $g$, aggregate labor demand in the South increase with the rate of imitation $\mu$. Similarly, holding constant the rate of imitation, demand for Southern labor increases with the rate of innovation:

$$
\frac{\partial L_{d}^{S}}{\partial g}=\frac{k a_{I}\left[\mu(\mu-\alpha \rho) \theta^{\varepsilon}+\alpha \theta \rho \mu+2 \theta g \mu+\alpha \theta g^{2}\right]}{(\mu+g)^{2}(1-\alpha) \theta^{\varepsilon}}>0
$$

where we have assumed that $\mu>\alpha \rho$.

Thus, the Southern labor market constraint (i.e. the $S S$ curve) is downward sloping in the $(g, \mu)$ space:

$$
\left.\sigma^{S}(g, \mu) \equiv \frac{d \mu}{d g}\right|_{L_{d}^{S}=L^{S}}=-\frac{\frac{\partial L^{S}(\mu, g)}{\partial g}}{\frac{\partial L^{S}(\mu, g)}{\partial \mu}}<0
$$

In other words, since the South has only a fixed amount of labor resources, an increase in the Southern rate of imitation $\mu$ implies that the rate of innovation $g$ that can be supported by the global economy must be lower.

Also, we have

$$
\frac{\partial L_{d}^{N}}{\partial \mu}=\frac{k a_{I}(\rho+g) A(\mu, g)}{(\rho+\mu+g)(1-\alpha) \theta^{\varepsilon}}>0
$$

i.e. the higher the rate of imitation $\mu$, the higher the demand for Northern labor. The logic for this is as follows. Since FDI is endogenously determined, a higher rate of imitation makes FDI less attractive to Northern firms. For a fixed rate of innovation, the demand for Northern workers is inversely related to the flow of FDI.

Next consider how an increase in the rate of innovation effects aggregate labor demand in the North. Recall that demand for Northern labor comes from innovation $\left(L_{n}^{N} \equiv a_{N} g\right)$ and from production $\left(L_{p}^{N} \equiv n_{N} x^{N}\right)$. It is obvious that an increase in $g$ raises labor demand in innovation $\left(L_{n}^{N}\right)$. On the production side, labor demand can be written as

$$
L_{p}^{N} \equiv \frac{n_{N}}{n} \frac{a_{N} \alpha(\rho+g)}{(1-\alpha)} \text { where } \frac{n_{N}}{n}=\frac{g}{\phi+g}
$$

which immediately implies that if $\frac{n_{N}}{n}$ were to increase in $g$, then it must be that $L_{p}^{N}$ (and therefore aggregate labor demand) in the North increases 
in $g$. Further note from above that if $\phi$ were independent of $g$, it would immediately follow that $\frac{n_{N}}{n}$ increases in $g$. This thought experiment is useful for highlighting the role of the flow of FDI in our model: if the flow of FDI flow were invariant to the rate of innovation, labor demand in the North would necessarily increase with the rate of innovation. However, Remark 2 notes that the flow of FDI and the rate of innovation are positively related. This raises the possibility that $\frac{n_{N}}{n}$ might decrease with $g$. Intuitively, such a situation could arise since the elasticity of the flow of FDI with respect to the rate of innovation exceeds unity. Despite this, we show in the appendix that labor demand in the North necessarily increases with the rate of innovation:

$$
\frac{\partial L_{d}^{N}}{\partial g}>0
$$

As a result, like the Southern labor market constraint, the Northern labor market constraint (i.e. the $N N$ curve) is also downward sloping in the $(g, \mu)$ space:

$$
\left.\sigma^{N}(g, \mu) \equiv \frac{d \mu}{d g}\right|_{L_{d}^{N}=L^{N}}=-\frac{\frac{\partial L_{d}^{N}}{\partial g}}{\frac{\partial L_{d}^{N}}{\partial \mu}}<0
$$

It is worth emphasizing the role FDI plays in this context: in the absence of FDI, in a variety expansion product cycle model such as Grossman and Helpman (1991b), the Northern market labor constraint is actually upward sloping in the $(g, \mu)$ space. This is because when imitation is the only channel via which production is reallocated internationally, an increase in the rate of imitation frees up Northern labor for use in innovation thereby generating a positive feedback between imitation and innovation. By contrast, in our model imitation targets production by multinationals and by slowing down FDI, an increase in the rate of imitation actually pulls Northern resources out of innovation and into production.

For a unique steady state equilibrium to exist, the $S S$ curve and the $N N$ curve must have a unique intersection in the $(g, \mu)$ space. We have already noted that both curves are downward sloping. Neither curve intersects the vertical axis and we show in the appendix that under minor conditions, the horizontal intercept $\left(g^{s}\right)$ of the $S S$ curve is larger than that $\left(g^{n}\right)$ of the $N N$ curve . The latter property means that when the rate of imitation is near zero, the rate of innovation required for the Southern market to be 
in equilibrium is greater relative to the required rate of innovation for the Southern market to be in equilibrium. This is quite intuitive: when the rate of imitation is zero, Southern resources are utilized only by multinationals for their production activities whereas Northern resources are used up in both innovation and production. As a result, when imitation is non-existent labor market equilibrium in the South calls for a greater rate of innovation than that in the North since the only activity generating labor demand - i.e. FDI - is positively related to the rate of innovation.

Given these properties of the two curves, any intersection of the two curves will be unique if the $N N$ curve is steeper than the $S S$ curve: i.e. $\sigma^{r} \equiv\left|\sigma^{N}\right| /\left|\sigma^{S}\right|>1$. We can show that $\sigma^{r}>1$ iff $a_{R} \equiv a_{N} / a_{I}$ exceeds some threshold $a_{R}^{*}$, where $a_{R}^{*}$ is a function of exogenous parameters and the rates of imitation and innovation. Furthermore, as $\rho$ approaches zero, $a_{R}^{*}$ can be shown to be decreasing in the rate of imitation $\mu$. In other words, for $\rho$ close to zero, the required threshold $a_{R}^{*}$ is the highest (and therefore the most difficult to meet) at $\mu=0$. Next, it can be shown that at $\mu=\rho=0$, $a_{R}^{*}$ decreases in $\theta$ and at the lowest feasible value of $\theta$ (which is $1 / \alpha$ ), the condition $a_{R}>a_{R}^{*}$ is necessarily satisfied for all feasible $\alpha$. Thus, we proceed with the scenario where the $N N$ curve is steeper than the $S S$ curve and the two curves have a unique intersection that pins down the equilibrium of the global economy.

As was already noted, holding constant the rates of imitation $(\mu)$ and innovation $(g)$, an increase in the degree of Southern IPR protection $(k)$ increases labor demand in the South in all three activities (i.e. local imitation, production by Southern firms, and production by multinationals). This is equivalent to an inward shift in the Southern labor market constraint in the $(g, \mu)$ space. Further note that holding constant $g$ and $\mu$, an increase in $k$ effects the Northern labor market constraint via its effect on the flow of FDI $\phi$. Given that the flow of FDI increases in the Southern IPR index $k$, it follows that labor demand in the North $L^{N}(\mu, g)$ (i.e. the left hand side of equation 42) decreases with $k$. The effect of a strengthening of IPR protection in the South on equilibrium rates of imitation and innovation can now be derived. As IPR protection in the South increases, the Southern labor market constraint (i.e. the $S S$ curve) shifts down while the Northern constraint (i.e. the $N N$ curve) shifts up. These shifts in the two constraints deliver one of our key results: 
Proposition 2: A strengthening of IPR protection in the South decreases the Southern rate of rate of imitation ( $\mu$ ) while it increases the Northern rate of innovation $(g): \frac{d \mu}{d k}<0<\frac{d g}{d k}$.

Figure 2 drawn in the $(g, \mu)$ space illustrates Proposition $2 .{ }^{16}$

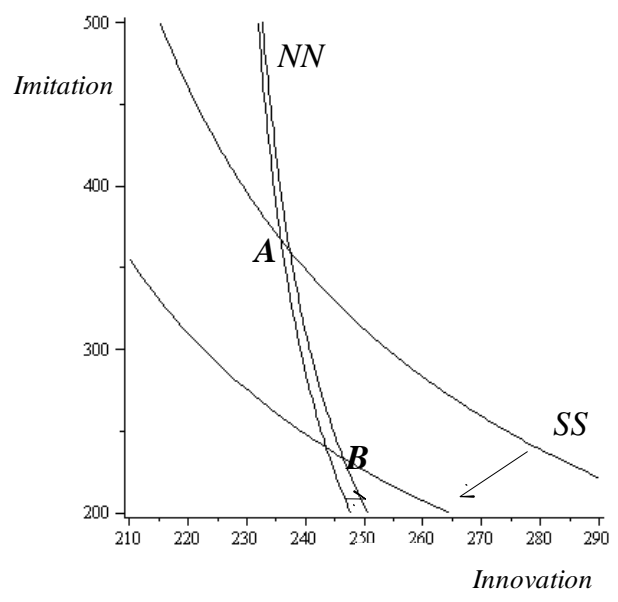

Figure 2: Effects of an increase in Southern IPR protection on imitation and innovation

The $N N$ curve illustrates the Northern resource constraint whereas the $S S$ curve denotes the Southern one. In Figure 2, the $N N$ curve is relatively steeper because of the fact that while the rate of innovation is determined primarily by the size of the Northern economy (since only the North innovates), the rate of imitation is determined primarily by the size of the Southern one (since only the South imitates). Of course, the North-South flow of FDI is what links the two resource constraints to each other.

Point $A$ denotes the initial steady state equilibrium. Now suppose that Southern IPR protection is strengthened (i.e. $k$ increases). In Figure 2, this implies an inward shift in the Southern resource constraint and an outward shift in the Northern constraint. Why the Southern constraint shifts has already been explained: all three activities in the South become more resource intensive and this effectively reduces the resource base. The Northern constraint shifts out because of the FDI response: as the flow of North-South FDI

\footnotetext{
${ }^{16}$ The following parameters were used to generate Figure 1: $L^{S}=200, L^{N}=450$, $a_{N}=1, a_{I}=.6, \rho=1 / 10, \theta=2$, and $\alpha=1 / 2$. The index of Southern IPR protection $k$ was increased by $10 \%$ (from 1 to 1.1).
} 
increases, more Northern resources become available for innovation. The outward shift in the Northern constraint is relatively smaller because the North is affected via a single, indirect channel (i.e. through the response of NorthSouth flow of FDI) whereas the effect on the South is a more direct one and it occurs via all three activities that take place there. As shown in Figure 2 , these shifts in the two resource constraints caused by a strengthening of IPR protection in the South imply that in the new steady state equilibrium $B$ the Southern rate of imitation is significantly lower than that at $A$ while the Northern rate of innovation is higher. ${ }^{17}$

Thus, from the perspective of the North, stronger Southern IPR enforcement in our model generates a rather classical trade-off between a static welfare loss and a dynamic welfare gain: the static loss being the decrease in real wages (or in its terms of trade since the relative price of Northern exports is determined by the relative wage) and the dynamic gain being the increase in the rate of innovation. What is noteworthy, however, is that the trade-off in the North results from changes in the IPR policy of the South.

We should emphasize that the properties of the model noted in Remarks 2 and 3 are quite crucial since these establish a positive feedback between FDI and innovation and a negative feedback between these two variables and the rate of imitation. As long as a strengthening of Southern IPR protection discourages imitation, its positive effects on innovation and FDI are implied by Remark 3. For innovation and FDI to be affected negatively by a strengthening of Southern IPR protection, our model would need to have the somewhat strange property that an increase in the resource requirement for imitation (as measured by $k a_{I}$ ) increases the rate of Southern imitation. Due to the complexity of the fully endogenous model, we cannot provide an analytical proof that rules out this unlikely possibility; however, we have not been able to find any sets of parameter values under which it arises.

Now briefly consider the case where a Southern imitator's flow profit from imitation equal $\pi_{k}^{S}=(1-k) \pi^{S}=(1-k)(\theta-1) w^{S} x^{S}$ where $k$ determined the degree of IPR protection and $0 \leq k \leq 1$. Under such a formulation, the Northern labor market equilibrium condition is unaltered whereas the other

\footnotetext{
${ }^{17}$ In a two-country model where both countries invest in labor saving innovation, Taylor (1994) finds that the global innovation and technology transfer are both higher when countries offer the same degree of IPR protection to innovating firms regardless of their national origin relative to when they offer such protection to only their own firms.
} 
two equilibrium conditions are slightly modified. In equation (39) we simply need to replace $1 / k$ by $(1-k)$ whereas in equation (30) the same substitution is needed in the second and third terms of the LHS; in the first term of the same equation, $k$ needs to be simply replaced by 1 . It is straightforward to show that results obtained under our cost based formulation of IPR protection continue to hold under thus profit-tax formulation.

Finally, we note how an improvement in R\&D productivity (i.e. a decrease in $a_{N}$ ) affects the North-South flow of FDI as well as the global allocation of production, once the effects on innovation and imitation are taken into account. First note that a decrease in $a_{N}$ has no direct effect on the $S S$ constraint whereas the effect on the $N N$ constraint is essentially the same as that an increase in the Northern labor supply - i.e. in figure 1, the $N N$ curve shifts out. This immediately implies that with an increase in Northern R\&D productivity, the rate of imitation decreases whereas the rate of innovation increases. Relying on arguments similar to those used to derive the effects of Southern IPR protection, we directly state the following:

Proposition 3: With an increase in the R\&D productivity of Northern firms (i.e. a decrease in $a_{N}$ ), the rate of innovation, the North-South flow of FDI, the share of Southern production in the hands of Northern multinationals, and the sales of multinationals relative to other firms, all increase whereas the rate of imitation decreases.

\subsection{Effects of FDI policies}

Many countries implement policies designed to attract FDI, perhaps with the hope of spurring local industrial development (see UNCTAD, 2003). Quite often such policies take the form of fiscal incentives under which multinationals that invest locally are offered reduced tax rates. Are such policies justifiable? To address this question, suppose that the South undertakes a policy of offering an incentive to Northern multinationals that lowers the profit tax $t$ on Northern multinationals from. What are the consequences of such a policy? First note that when such a profit tax is in place, a typical Northern multinational's after-tax profit equals

$$
\pi_{t}^{M}=(1-t) \pi^{M}=(1-t)\left(p^{M}-w^{S}\right) x^{M}=\frac{\theta(1-\alpha)(1-t) w^{S} x^{M}}{\alpha}
$$


It is straightforward to show that when a multinational's profit is $\pi_{t}^{M}$ (as opposed to $\pi^{M}$ ), the Northern relative wage equals

$$
w_{t}^{R}=\theta\left[\frac{1}{1-t}\left(1+\frac{\mu}{\rho+g}\right)\right]^{\frac{1}{\varepsilon-1}}
$$

from where it is immediate that a reduction in the profit tax $t$ on multinationals (which is the same as a tax incentive for FDI) increases the Southern relative wage. The intuition is simple: the use of FDI incentives makes the South a more attractive production location and shifts labor demand away from the North in favor of the South.

Under a tax on multinationals, the North-South flow of FDI is given by

$$
\phi_{t}=\frac{g}{\frac{a_{N} \theta^{\varepsilon}}{A_{t}(\mu, g) k a_{I}}-1} \text { where } A_{t}(\mu, g)=\left[\frac{(\rho+g)(1-t)}{\rho+g+\mu}\right]^{\frac{1}{\alpha}}
$$

Since $A_{t}(\mu, g)$ decreases in $t$, it is clear from above that holding constant the rates of innovation $(g)$ and imitation $(\mu)$, the North-South flow of FDI $(\phi)$ increases with a decrease in the FDI tax rate $t$. Of course, how the equilibrium flow of FDI responds to the use of an FDI incentive depends on how the rates of innovation $(g)$ and imitation $(\mu)$ respond to such a policy. Note that the Southern resource constraint is unaffected by the FDI tax rate $t$ whereas the Northern constraint is affected via the North-South flow of FDI. But since this flow is inversely related to the tax rate $t$, it implies that a reduction in $t$ results in an outward shift in the $N N$ curve in figure 1 without having any affect on the $S S$ curve. This implies that a reduction in the Southern tax rate $t$ on multinationals increases the rate of innovation (g) and the North-South flow of FDI ( $\phi)$ whereas it decreases the Southern rate of imitation $(\mu)$.

In the presence of the FDI tax, equation (38) (which follows from free entry into innovation and imitation) becomes

$$
\frac{n_{S}}{n} \frac{\theta^{\varepsilon} a_{N}}{k a_{I}}\left[\frac{1}{1-t}\left(1+\frac{\mu}{\rho+g}\right)\right]^{\frac{\varepsilon}{\varepsilon-1}}=1
$$

Since the term in square brackets increases with $t$, it must be that $\frac{n_{S}}{n}$ decreases with $t$. In other words, a Southern policy of attracting FDI via a reduction in the tax rate $t$, increases the share of the global basket of goods 
that is produced in the South. Furthermore, since $\frac{n_{I}}{n_{M}}=\frac{\mu}{g}$, such a policy change towards FDI also shifts production in favor of Northern multinationals and away from Southern imitators. Finally, consider the labor market consequences of such a policy. It follows immediately from the formula for the North-South relative wage (see 43) that a reduction in $t$ decreases the South's relative wage $\left(1 / w_{t}^{R}\right)$. Furthermore, such a policy change lowers real wages in the North while increasing them in the South.

Corollary 3: A reduction in the Southern tax rate on multinationals increases the South's wage relative to the North as well as the real wages of Southern workers.

Finally, note that the price effects of a reduction in the Southern tax rate on multinationals are quite like those of a strengthening of its IPR protection: both types of policies lower prices of those goods whose production shifts from the North to the South while increasing prices of those goods whose production stays in the hands of multinationals as opposed to Southern imitators.

\section{Conclusion}

Opinions regarding the strengthening of IPR regimes in developing countries required under the TRIPS agreement of the WTO vary remarkably across individuals and nations. While the issue is multi-faceted and complex, the following statement broadly captures the disparity in views regarding TRIPs: developing countries have tended to argue that stronger IPR regimes in their markets will have adverse effects on prices without having much of a positive impact on innovation whereas developed countries have stressed that not only innovation, but also FDI flows would respond strongly to such reforms. In principle, an increase in FDI has the potential to offer two major sources of welfare gains. One, it can lower prices by shifting production to lower

cost locations. Two, FDI has the potential to encourage Southern industrial development by introducing new technologies into the South. In this paper, we have presented a general equilibrium North-South product cycle model with a degree of endogenity that allows us to assess these arguments in a unified framework. 
The major results of our core model are as follows. First, we find that a strengthening of IPR protection in the South discourages imitation. Second, it increases FDI to a degree that the Southern production base actually expands - i.e. the decline in Southern imitative activity is more than offset by the increase in the production activity of Northern multinationals who are drawn to the South because local IPR reform renders it a more attractive production location by reducing the risk of imitation. Third, while prices of those goods that are reallocated from firms producing in the North to multinationals fall, prices of goods that are reallocated from potential imitators to Northern multinationals increase. In other words, IPR reform in the South has conflicting effects on consumer welfare when viewed solely through the price channel. However, what actually matters for consumer welfare is purchasing power. And from this viewpoint, Southern IPR reform benefits the South since it increases not only the South's wage relative to the North but also the purchasing power of Southern consumers. By contrast, not only does the Northern relative wage decline, the real income of Northern workers also falters. It is worth emphasizing that only a general equilibrium model such as ours can help assess the full impact of the price changes that result from IPR reforms since these can be offset (or dominated) by the accompanying changes in wages. Finally, when innovation is endogenous, a strengthening of IPR protection in the South increases its rate. We should note that while the paper does not provide a full-fledged welfare analysis along the lines of Helpman (1993), the clarity with which the various channels that affect welfare emerge in the model does shed new light on a rather complex set of issues.

\section{Appendix}

In this appendix, we first provide some derivations omitted from the text and then discuss the relationship of our model to Lai (1998).

\subsection{Rate of imitation with $g$ exogenous}

When $g$ is exogenous, the equilibrium rate of imitation solves $L_{d}^{S}(\phi, \mu)=L^{S}$ which is the same as

$$
k a_{I} \frac{g \mu}{g+\mu}+\frac{\theta \alpha k a_{I}}{1-\alpha} \frac{g(\rho+g)}{\theta^{\varepsilon}(g+\mu)}+\frac{\alpha k a_{I}}{1-\alpha} \frac{\mu(\rho+g)}{g+\mu}=L^{S}
$$


Rearranging, we have

$$
\frac{\alpha k a_{I}}{1-\alpha} \frac{\theta g(\rho+g)}{\theta^{\varepsilon}}+\mu\left[k a_{I} g++\frac{\alpha k a_{I}(\rho+g)}{1-\alpha}\right]=L^{S}(g+\mu)
$$

which is the same as

$$
B+\mu C=L^{S}(g+\mu)
$$

where

$$
0<B \equiv \frac{\alpha k a_{I}}{1-\alpha} \frac{\theta(\rho+g)}{\theta^{\varepsilon}}<C \equiv k a_{I} g+\frac{\alpha k a_{I}(\rho+g)}{1-\alpha}
$$

Solving for $\mu$ yields

$$
\mu=\frac{g\left(L^{S}-B\right)}{C-L^{S}}
$$

It is straightforward to show that $\mu$ increases in $L^{S}$ whereas it decreases in the degree of Southern IPR protection $k$.

\subsection{Slope of $N N$ curve}

We already noted in the main text that $\frac{\partial L^{N}(\mu, g)}{\partial \mu}>0$. Direct calculations yield

$$
\frac{\partial L^{N}(\mu, g)}{\partial g}=\frac{\theta^{\varepsilon}(\rho+\mu+g) a_{N}-a_{I} A(\mu, g)[\alpha(\rho+\mu+g)-\mu]}{(\rho+\mu+g)(1-\alpha) \theta^{\varepsilon}}
$$

From where it follows that a sufficient condition for $\frac{\partial L^{N}(\mu, g)}{\partial g}>0$ is that $\frac{a_{N}}{a_{I}}>\frac{1+\alpha}{\theta^{\varepsilon}}$. This is because $(\rho+g)\left[\theta^{\varepsilon} a_{N}-\alpha a_{I} A(\mu, g)\right]>0$ due to the fact that $A(\mu, g)<1, \alpha<1, a_{N} \geq a_{I}$ and $\theta^{\varepsilon}>1$. Next note that the condition $\frac{a_{N}}{a_{I}}>\frac{1+\alpha}{\theta^{\varepsilon}}$ is satisfied for all feasible parameter values: since $a_{N} \geq a_{I}$, at the lowest feasible value of $a_{N}$ this condition becomes $\theta^{\varepsilon}>1+\alpha$ which necessarily holds since $\theta>1 / \alpha$.

\subsection{Horizontal intercepts of the two curves}

It is trivial to observe that neither curve can intersect the vertical axis since labor demand in each country approaches zero as the growth rate approaches zero. The $N N$ curve intersects the horizontal axes at $g^{n}$ where

$$
g^{n} \equiv \frac{\theta^{\varepsilon} L^{N}(1-\alpha)-\alpha \rho\left(a_{N} \theta^{\varepsilon}-a_{I}\right)}{a_{N} \theta^{\varepsilon}-\alpha a_{I}}
$$


Similarly, the $S S$ curve intersects the horizontal axis at $g^{s}$ where

$$
g^{s} \equiv \frac{L^{S}(1-\alpha) \theta^{\varepsilon}-\alpha \theta a_{I} \rho}{\theta a_{I} \rho}
$$

From where it follows that

$$
g^{s}>g^{n} \text { iff } L^{S}>\overline{L^{S}} \text { where } \overline{L^{S}} \equiv \frac{\left(L^{N}+\rho a_{N}\right) \alpha \theta a_{I}}{\theta^{\varepsilon} a_{N}-\alpha a_{I}}
$$

We assume that $L^{S}>\overline{L^{S}}$.

\subsection{Relationship to Lai's model}

Our model differs from Lai's in one key respect: imitation is endogenous in our model whereas it is exogenous in his. Setting $\theta=1$ and assuming $\mu$ is exogenous simplifies our model down to Lai's. In that case, the two endogenous variables (i.e. $g$ and $\phi$ ) must satisfy the following two equations:

$$
\left[\frac{\phi}{g}\left(\frac{g+\mu \alpha^{-\varepsilon}}{g+\mu}\right)\left(\frac{L_{N}-a g}{L_{S}}\right)\right]^{\alpha}=\frac{\rho}{\rho+\mu}
$$

and

$$
\left(\frac{1-\alpha}{\alpha}\right)\left(L_{N}-a g\right)\left(\frac{\phi}{g}+1\right)=a \rho
$$

The following result is proved in Lai (1998): a strengthening of Southern IPR protection (i.e. a decrease in the rate of imitation $\mu$ ) increases the Northern rate of innovation $g$. The proof proceeds in a straightforward fashion: the implicit function theorem is applied to the above equation to determine the sign of $\frac{d g}{d \mu}$.

\section{References}

[1] Branstetter, L., R. Fisman, and F. Foley, 2006, Do Stronger Intellectual Property Rights Increase International Technology Transfer? Empirical Evidence from U.S. Firm-Level Data, Quarterly Journal of Economics 121, 321-349. 
[2] Branstetter, L., R. Fisman, F. Foley, and K. Saggi, 2007, Intellectual Property Rights, Imitation, and Foreign Direct Investment: Theory and Evidence, NBER Working paper 13033.

[3] Chaudhuri, S., P. Goldberg, and P. Jia, 2006, Estimating the Effects of Global Patent Protection in Pharmaceuticals: A Case Study of Quinolones in India, American Economic Review 96, 1477-1514.

[4] Desai, M., F. Foley, and J. Hines, 2004, Foreign Direct Investment in a World of Multiples Taxes, Journal of Public Economics 88, 2727-2744.

[5] Dixit, A., and J. Stiglitz, 1977, Monopolistic Competition and. Optimum Product Diversity, American Economic Review, 67, 297-308.

[6] Eaton, J. and S. Kortum, 1996, Trade in Ideas: Patenting and Productivity in the OECD, Journal of International Economics 40, 1-28.

[7] Eaton, J. and S. Kortum, 1999, International Technology Diffusion: Theory and Measurement, International Economic Review 40, 537-570.

[8] Ginarte, J. and W. Park, 1997, Determinants of Patent Rights: A CrossNational Study, Research Policy 26, 283-301.

[9] Glass, A.J. and K. Saggi, 2002, Intellectual Property Rights and Foreign Direct Investment, Journal of International Economics 56, 387-410.

[10] Glass, A.J. and X. Wu, 2007, Intellectual Property Rights and Quality Improvement, Journal of Development Economics 82, 393-415.

[11] Grossman, G.M. and E. Helpman, 1991a, Innovation and Growth in the Global Economy, Cambridge, MIT press.

[12] Grossman, G.M. and E. Helpman, 1991b, Endogenous Product Cycles, Economic Journal 101, 1214-1229.

[13] Grossman, G.M. and E. L.C. Lai, 2004, International Protection of Intellectual Property, American Economic Review 94, 1635-1653.

[14] Helpman, E., 1993, Innovation, imitation, and intellectual property rights, Econometrica 61, 1247-1280. 
[15] Javorcik, B., 2004, The Composition of Foreign Direct Investment and Protection of Intellectual Property Rights in Transition Economies, European Economic Review, 48, 39-62.

[16] Lai, E., 1998, International Intellectual Property Rights Protection and the Rate of Product Innovation, Journal of Development Economics 55, 133-153.

[17] Mansfield, E., 1994, Intellectual Property Protection, Foreign Direct Investment, and Technology Transfer, Discussion Paper 19, International Finance Corporation, Washington DC.

[18] Markusen, J.R., 2001, Contracts, Intellectual Property Rights, and Multinational Investment in Developing Countries, Journal of International Economics 53, 189-204.

[19] Markusen, J.R.,1995, The Boundaries of Multinational Enterprises and the Theory of International Trade, Journal of Economic Perspectives 9, 169-190.

[20] Maskus, K.E., 2000, Intellectual Property Rights in the Global Economy, Institute for International Economics, Washington DC.

[21] Maskus, K.E. and C. McDaniel, 1999, Impacts of the Japanese Patent System on Productivity Growth, Japan and the World Economy 11, 557-574.

[22] Mayer, T. and E. Pfister, 2001, Do Stronger Patent Rights Attract Foreign Direct Investment? Evidence from French Multinationals' Location, Region et. Development 13, 99-122.

[23] Mutti, J. and H. Grubert, 2004, Empirical Asymmetries in Foreign Direct Investment and Taxation. Journal of International Economics 62, 337-358.

[24] Nunnenkamp, P. and J. Spatz, 2004, Intellectual Property Rights and Foreign Direct Investment: a Disaggregated Analysis, Weltwirtschaftliches Archiv (Review of World Economics) 140, 393-414. 
[25] McCalman, P., 2001, Reaping What you Sow: An Empirical Analysis of International Patent Harmonization. Journal of International Economics $55,161-186$.

[26] Ordover, J., 1991, Patent System for both Diffusion and Exclusion, Journal of Economic Perspectives 5, 43-60.

[27] Park, W., 2008, Intellectual Property Rights and International Innovation, in, Maskus, K., ed., Frontiers of Economics and Globalization: Intellectual Property Rights and Globalization, Elsevier, Amsterdam.

[28] Romer, P., 1990, Endogenous Technical Change, Journal of Political Economy 98, S71-S102.

[29] Sakakibara, M. and L. Branstetter, 2001, Do Stronger Patents Induce More Innovation? Evidence from the 1988 Japanese Patent Reforms, Rand Journal of Economics 32, 771-100.

[30] Taylor, Scott M., 1994, TRIPS, Trade, and Growth, International Economic Review 35, 361-381.

[31] UNCTAD, 2003, World Investment Report 2003: FDI Policies for Development: National and International Perspectives, United Nations, New York.

[32] Westphal, L.E. Kim, L., and Dahlman, C.J, 1985, Reflections on the Republic of Korea's acquisition of technological capability, in Rosenberg, N., Frischtak, C. (eds),International Transfer of Technology: Concepts, Measures, and Comparisons, Praeger Press, New York, NY. 